IJRMMS-D-14-00436 - edited and approved by editor

\author{
Technical Note
}

\title{
Experimental determination of single-crystal halite thermal conductivity, diffusivity and specific heat from $-75^{\circ} \mathrm{C}$ to $300^{\circ} \mathrm{C}$
}

\author{
Alexander Urquhart and Stephen Bauer \\ Geomechanics Department, Sandia National Laboratories, New Mexico, P.O. Box 5800, \\ Albuquerque, NM 87185-1033, USA \\ * Corresponding author: \\ sjbauer@sandia.gov \\ 1-505-844-9116 (corresponding author) \\ Key words: Single-crystal halite, Thermal conductivity, Thermal diffusivity, Specific heat, \\ Temperature dependence, Salt storage, Rock Mechanics
}




\section{Introduction}

\subsection{Background and objectives}

The thermal properties of halite have broad practical importance, from design and longterm modeling of nuclear waste repositories to analysis and performance assessment of underground natural gas, petroleum and air storage facilities. This work was motivated by a need for thermal conductivity values in a mixture theory model used to determine bulk thermal conductivity of actively reconsolidating crushed salt in radioactive waste storage sites [1-2]. The thermal conductivity of porous crushed salt is modeled with a generalized mixture theory equation-the geometric mean of rock conductivity and pore conductivity, which estimates bulk thermal conductivity of a two-medium material. Such a model is based on accurate thermal conductivity values of pure materials. The thermal conductivity of air is well established (e.g., [3-5]), but such data for pure, non-porous halite is scant and dated. We therefore determined thermal conductivity values, as well as thermal diffusivity and specific heat, for a single, optically clear crystal of halite.

\subsection{Previous work}

Because salt formations are used to store liquid and gaseous petroleum products, as well as compressed air and hydrogen, domal and bedded rock salt have been the subject of extensive thermal, mechanical and hydrologic study at various temperatures and pressures. Rock salt is a composite of individual crystals, however, and, in addition to crystal boundaries, may contain deformation-induced microfracturing or impurities such as anhydrite and clay minerals [6]. Little thermal property data exists for pure, single-crystal salt. Birch and Clark [7-8] developed an early dataset from $0^{\circ} \mathrm{C}$ to $400^{\circ} \mathrm{C}$, using a guarded heat flow device to measure thermal resistivity, which is the reciprocal of thermal conductivity. Smith [9] used a laser flash thermal diffusivity technique to indirectly measure thermal conductivity of coated optically transparent halite from $25^{\circ} \mathrm{C}$ to $650^{\circ} \mathrm{C}$. This study acknowledged problems inherent to the method, however, and suggested that a method with a single, direct measurement would be more desirable.

\section{Methods and Materials}

This study extends the experimental determination of single-crystal halite thermal conductivity to $-75^{\circ} \mathrm{C}$ with a direct measurement technique. Sample material consisted of a 
single optically clear crystal of halite collected from a coarse-grained section of the Hockley Salt Mine in Harris County, Texas. The crystal has a width of roughly $75 \mathrm{~mm}$ and height of $50 \mathrm{~mm}$. The sample is uncoated and unjacketed, so there is no interference from other material properties.

Measurements were taken with the transient plane source Hot Disk Thermal Constants Analyzer (TCA). The transient plane source method uses a planar, Kapton-coated nickel coil that functions as both a heat source and resistance thermometer capable of detecting temperature changes as slight as 1 ten-thousandth of a degree Kelvin. (Note: degree $\mathrm{K}$ and degree Celsius are used interchangeably in this paper) The halite crystal is well above the minimum TCA sample size of $3 \mathrm{~mm}$ in height by $7 \mathrm{~mm}$ in diameter; there is no maximum sample size. The halite crystal is cleaved along a crystal plane and the TCA coil is sandwiched between the two halves (Fig. 1) using less than 5 psi mounting pressure. Passing a current through the coil increases its temperature by as much as a few degrees Celsius and causes a pulse of heat to enter the sample. The coil temperature then decreases over time as a function of the sample's ability to conduct heat away from the coil. By monitoring the coil temperature over time, the TCA simultaneously calculates sample thermal conductivity, thermal diffusivity and specific heat.

Measurements of physical quantities are subject to uncertainties in the measurements. Variability in the results of repeated measurements arises because variables that can affect the measurement result are impossible to hold constant. The capability of the measurement instrument used herein, for measuring thermal transport properties, has been demonstrated for a large variety of materials. It is recognized that beyond considerations of sample-sensor contact, the heating power, measuring time, and radius of the measurement disk were carefully selected to maximize accurate results. The selection/optimization of these parameters was in part based on understanding the instrument, and on experience gained from hundreds of measurements made in advance of those reported herein. Measurement accuracy for thermal conductivity is +/$5 \%$ and reproducibility of $+/ 2 \%$ using this instrument on standard materials over a range extending beyond that studied here.

Thermal conductivity measurements were made at ambient pressure and moisture conditions, at a range of temperatures from $-75^{\circ} \mathrm{C}$ to $300^{\circ} \mathrm{C}$. Measurements at $-75^{\circ} \mathrm{C},-50^{\circ} \mathrm{C}$, $25^{\circ} \mathrm{C}$ and $0{ }^{\circ} \mathrm{C}$ were made in a liquid nitrogen-cooled environmental chamber; measurements at $25^{\circ} \mathrm{C}, 40^{\circ} \mathrm{C}, 50^{\circ} \mathrm{C}$ and in 50 -degree increments to $300^{\circ} \mathrm{C}$ were made in a computer-controlled 
oven. One series of five measurements was made at every temperature, followed by a second series, to show reproducibility, of three measurements at each temperature except $-75^{\circ} \mathrm{C}$. All measurements at each temperature within each series were within $1 \%$ of their average; the series averages at every temperature were within $2 \%$ of each other. The series averages are reported and discussed. The uncertainties in the temperature values reported are less than $1 \%$ and material property values are approximately $2 \%$.

\section{Results}

The averages of each measurement at each temperature are presented in Table 1. The thermal conductivity of single-crystal halite from $-75^{\circ} \mathrm{C}$ to $300^{\circ} \mathrm{C}$ is presented in Fig. 2, along with data reported by Birch and Clark [7-8] and Smith [9]. Thermal conductivity decreases with increasing temperature, falling from $9.975 \mathrm{~W} / \mathrm{mK}$ at $-75^{\circ} \mathrm{C}$ to $2.699 \mathrm{~W} / \mathrm{mK}$ at $300^{\circ} \mathrm{C}$. A trinomial curve with an R-squared value of 0.999 can be described as a function of $\mathrm{T}$, where $\mathrm{T}$ is temperature in Celsius:

$T \square$ ermal conductivity

$$
=\left(-2 \times 10^{-7} T^{3}\right)+\left(1 \times 10^{-4} T^{2}\right)-\left(3.17 \times 10^{-2} T\right)+6.8203
$$

The thermal diffusivity of single-crystal halite from $-75^{\circ} \mathrm{C}$ to $300^{\circ} \mathrm{C}$ is presented in Fig. 3. Thermal diffusivity decreases with increasing temperature, falling from $5.032 \mathrm{~mm}^{2} / \mathrm{s}$ at $-75^{\circ} \mathrm{C}$ to $1.396 \mathrm{~mm}^{2} / \mathrm{s}$ at $300^{\circ} \mathrm{C}$. A trinomial curve with an $\mathrm{R}$-squared value of 0.999 has the form:

$$
T \square \text { ermal diffusivity }=\left(-6 \times 10^{-8} T^{3}\right)+\left(5 \times 10^{-5} T^{2}\right)-\left(1.62 \times 10^{-2} T\right)+3.4974
$$

Note that these functions are best-fit curves for thermal conductivity and thermal diffusivity in range of test temperatures. Although they are good thermal properties estimates in this range, they do not represent an obvious natural relationship between the variables and should not be extrapolated to temperatures lower than $-75^{\circ} \mathrm{C}$ or higher than $300^{\circ} \mathrm{C}$.

The specific heat of single-crystal halite from $-75^{\circ} \mathrm{C}$ to $300^{\circ} \mathrm{C}$ is presented in Fig. 4 . Specific heat remains roughly constant as temperature increases, oscillating around an average of

approximately $1.98 \mathrm{MJ} / \mathrm{m}^{3} \mathrm{~K}$. The lowest value is $1.92 \mathrm{MJ} / \mathrm{m}^{3} \mathrm{~K}$, at $29^{\circ} \mathrm{C}$; the highest value is $2.05 \mathrm{MJ} / \mathrm{m}^{3} \mathrm{~K}$, at $75^{\circ} \mathrm{C}$. 


\section{Discussion}

Thermal conductivity measurements from this study average about $9 \%$ higher than halite measurements at the same temperatures from Birch and Clark [7-8], but data trends in the two studies closely mirror each other. Data from Smith [9] falls in the same approximate range, but decreases more linearly as temperature increases. Smith acknowledges problems inherent to the laser flash methodology, however. The sample must be coated and results show up to $10 \%$ variability for some materials. The technique can be used to produce data of "engineering quality" (within $+/-5 \%$ error).

The thermal properties determined in this study can be used to define parameters for the thermophysical models used to predict the behavior of salt storage facilities in response to temperature change. This study will be especially useful in modeling fractured, deformed, porous or impure rock salt. To predict the bulk thermal conductivity of porous reconsolidating crushed salt, for example, requires a mixture theory model based on the zero-porosity thermal conductivity of pure salt. We have provided data for such a model from $-75^{\circ} \mathrm{C}$ to $300^{\circ} \mathrm{C}$. Together with historical studies, this expands the scope of known halite thermal conductivity across of range of $725^{\circ} \mathrm{C}$, covering both cold and hot storage facility conditions.

\section{Conclusions}

Understanding halite single-crystal thermal properties is important in modeling the behavior of fractured or impure salt structures such as gas or radioactive waste storage facilities. Using a transient plane source technique, we measured thermal properties in a single crystal of halite from $-75^{\circ} \mathrm{C}$ to $300^{\circ} \mathrm{C}$. Thermal conductivity is strongly temperature-dependent and decreases by a factor of about 3.7 between the temperature extremes-from 9.975 to 2.699 $\mathrm{W} / \mathrm{mK}$. Thermal diffusivity and specific heat measurements were also collected over the same range of temperatures. Thermal diffusivity decreases by a factor of about 3.6 as temperature increases-from 5.032 to $1.396 \mathrm{~mm}^{2} / \mathrm{s}$. Specific heat shows no temperature dependence, oscillating around $1.98 \mathrm{MJ} / \mathrm{m}^{3} \mathrm{~K}$ as temperature increases.

These measurements reproduce historical high-temperature halite experiments and extend the lower temperature extreme of halite thermal properties datasets into cryogenic conditions. Such data are valuable for defining the parameters of many salt storage thermophysical models. 


\section{Acknowledgements}

This work was completed in the Geomechanics Laboratory at Sandia National Laboratories. Sandia National Laboratories is a multi-program laboratory managed and operated by Sandia Corporation, a wholly owned subsidiary of Lockheed Martin Corporation, for the U.S. Department of Energy's National Nuclear Security Administration under contract DE-AC0494AL85000. 


\section{References}

[1] Bauer SJ, Urquhart A. Thermophysical properties of reconsolidating crushed salt. Albuquerque (NM): Sandia National Laboratories; 2014 Mar. 94 p. Report No.: SAND20142240.

[2] Hansen FD, Bauer SJ, Broome ST, Callahan GD. Coupled thermal-hydrological-mechanical processes in salt: Hot granular salt consolidation, constitutive model and micromechanics. Albuquerque (NM): Sandia National Laboratories; 2012. 76 p. Report Nos.: FCRD-UFD-2012000422, SAND2012-9893. Supported by the US Department of Energy under contract DEAC04-94AL85000.

[3] Kadoya K, Matsunaga N, Nagashima A. Viscosity and thermal conductivity of dry air in the gaseous phase. J Phys Chem Ref Data 1985; 14:947-70.

[4] Kannuluik W, Carman E. The temperature dependence of the thermal conductivity of air. Aust J Sci Res, Ser A: Phys Sci 1951; 4:305-14.

[5] Stephan K, Laesecke A. The thermal conductivity of fluid air. J Phys Chem Ref Data 1985; 14:227-34.

[6] Stein CL. Mineralogy in the Waste Isolation Pilot Plant (WIPP) facility stratigraphic horizon. Albuquerque (NM): Sandia National Laboratories; 1985 Sep. 32 p. Report No.: SAND85-0321.

[7] Birch F, Clark H. The thermal conductivity of rocks and its dependence upon temperature and composition: Part I. Am J Sci 1940; 238:529-58.

[8] Birch F, Clark H. The thermal conductivity of rocks and its dependence upon temperature and composition: Part II. Am J Sci 1940; 238:613-35.

[9] Smith D. (1976), Thermal conductivity of halite using a pulsed laser. Oak Ridge (TN): Oak Ridge Y-12 Plant; 1976. 39 p. Report No.: Y/DA-7013. Contract No.: W-7405-eng-26. Supported by the US Energy Research and Development Administration. 


\section{Tables}

Table 1 Average values of single-crystal halite thermal conductivity (TC), thermal diffusivity (TD) and specific heat (SH) from $-75^{\circ} \mathrm{C}$ to $300^{\circ} \mathrm{C}$. 


\section{Figures}

Figure 1 A single crystal of halite is cleaved along a crystal plane. The TCA nickel coil heat source and resistance thermometer is then sandwiched between the two halves. [Note there are two files for Figure 1. They should be placed together as a single figure.]

Figure 2 Thermal conductivity measurements of single-crystal halite from this study compared to previously reported measurements.

Figure 3 Thermal diffusivity of single-crystal halite.

Figure 4 Specific heat of single-crystal halite. 


\begin{tabular}{llll}
\hline${ }^{\circ} \mathbf{C}$ & $\mathbf{T C}(\mathbf{W} / \mathbf{m K})$ & $\mathbf{T D}\left(\mathbf{m m}^{2} / \mathbf{s}\right)$ & $\mathbf{S H}\left(\mathbf{M J} / \mathbf{m}^{\mathbf{3}} \mathbf{K}\right)$ \\
\hline-75 & 9.975 & 5.032 & 1.982 \\
-50 & 8.592 & 4.381 & 1.961 \\
-25 & 7.625 & 3.949 & 1.932 \\
0 & 6.783 & 3.491 & 1.944 \\
25 & 6.054 & 3.162 & 1.915 \\
40 & 5.675 & 2.908 & 1.952 \\
50 & 5.488 & 2.778 & 1.976 \\
75 & 5.085 & 2.485 & 2.048 \\
100 & 4.658 & 2.319 & 2.009 \\
125 & 4.250 & 2.130 & 1.996 \\
150 & 3.911 & 2.001 & 1.960 \\
175 & 3.635 & 1.788 & 2.033 \\
200 & 3.389 & 1.691 & 2.004 \\
225 & 3.199 & 1.597 & 2.003 \\
250 & 3.024 & 1.515 & 1.997 \\
275 & 2.864 & 1.450 & 1.974 \\
300 & 2.699 & 1.396 & 1.934 \\
\hline
\end{tabular}



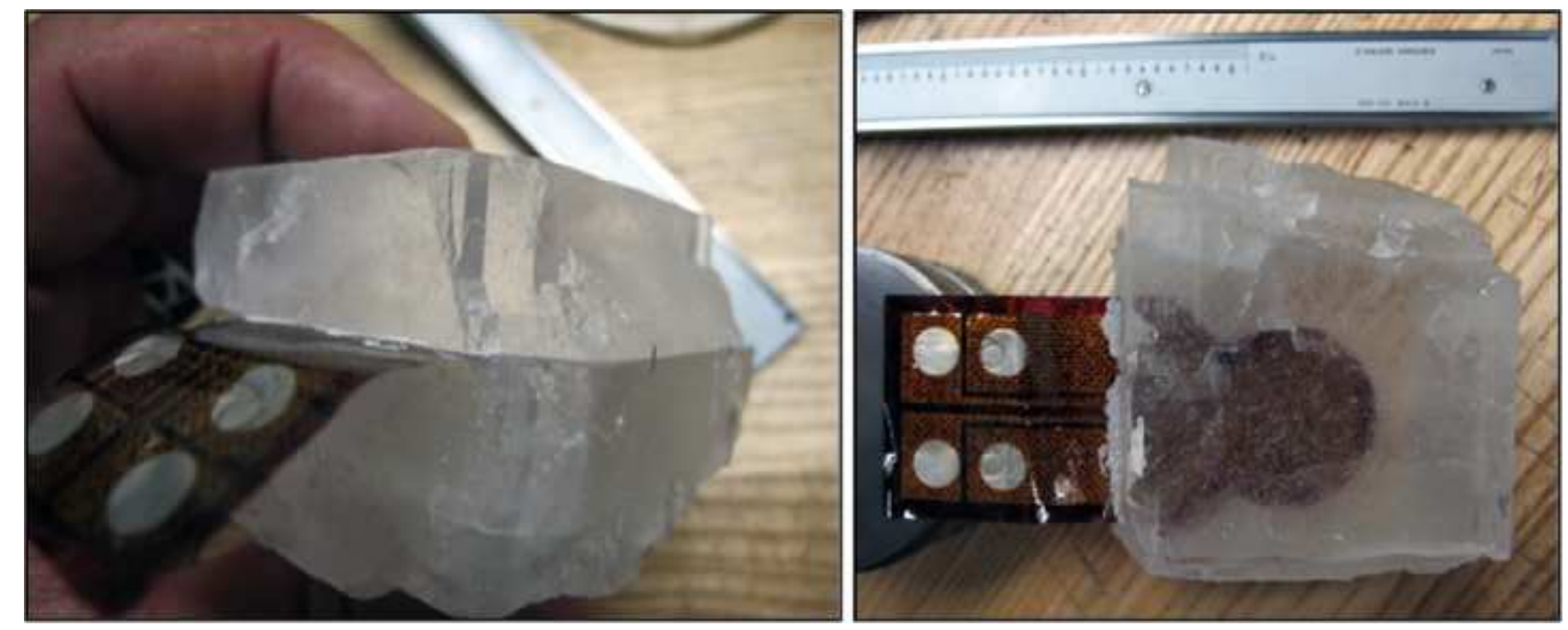
Figure 2

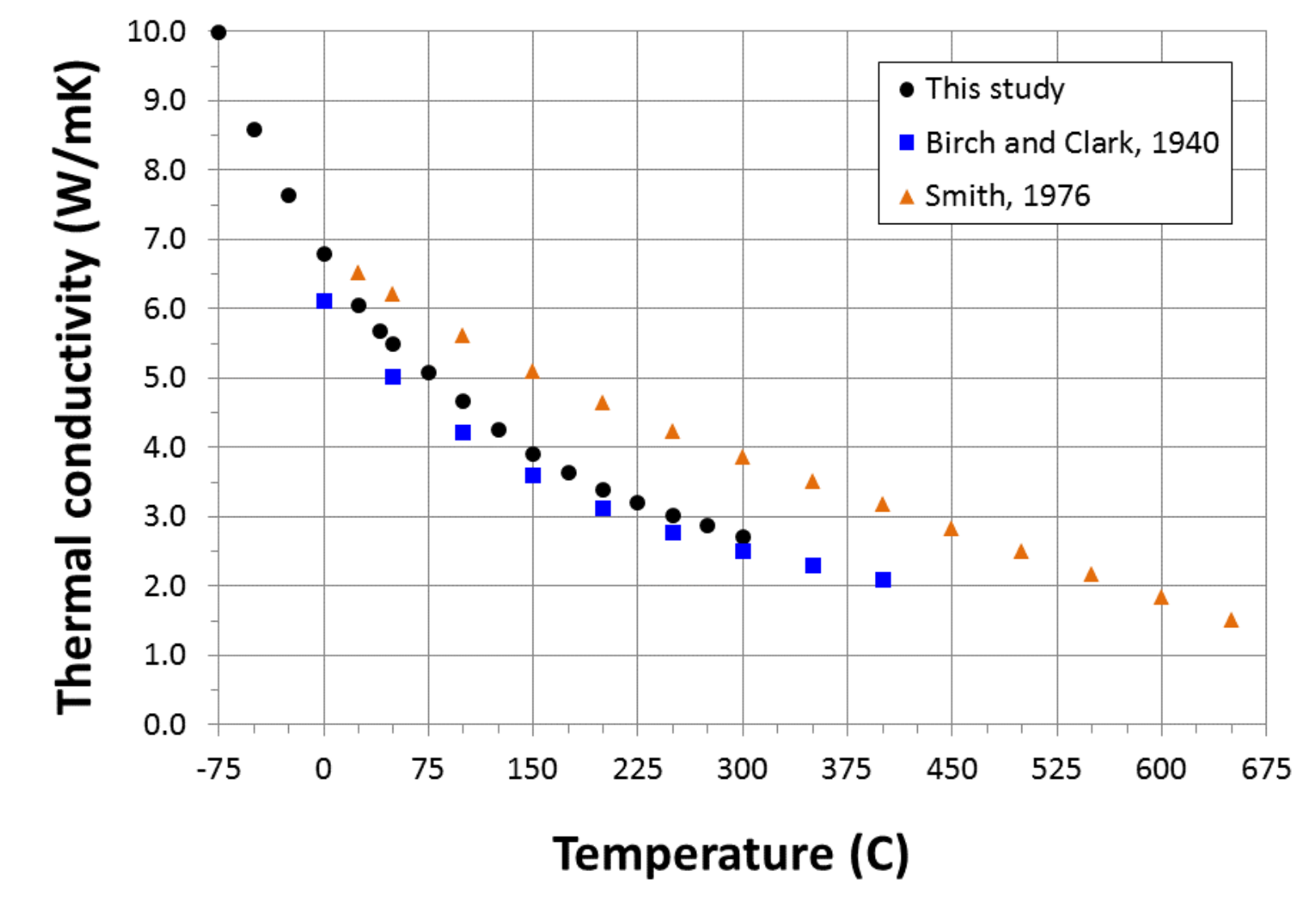




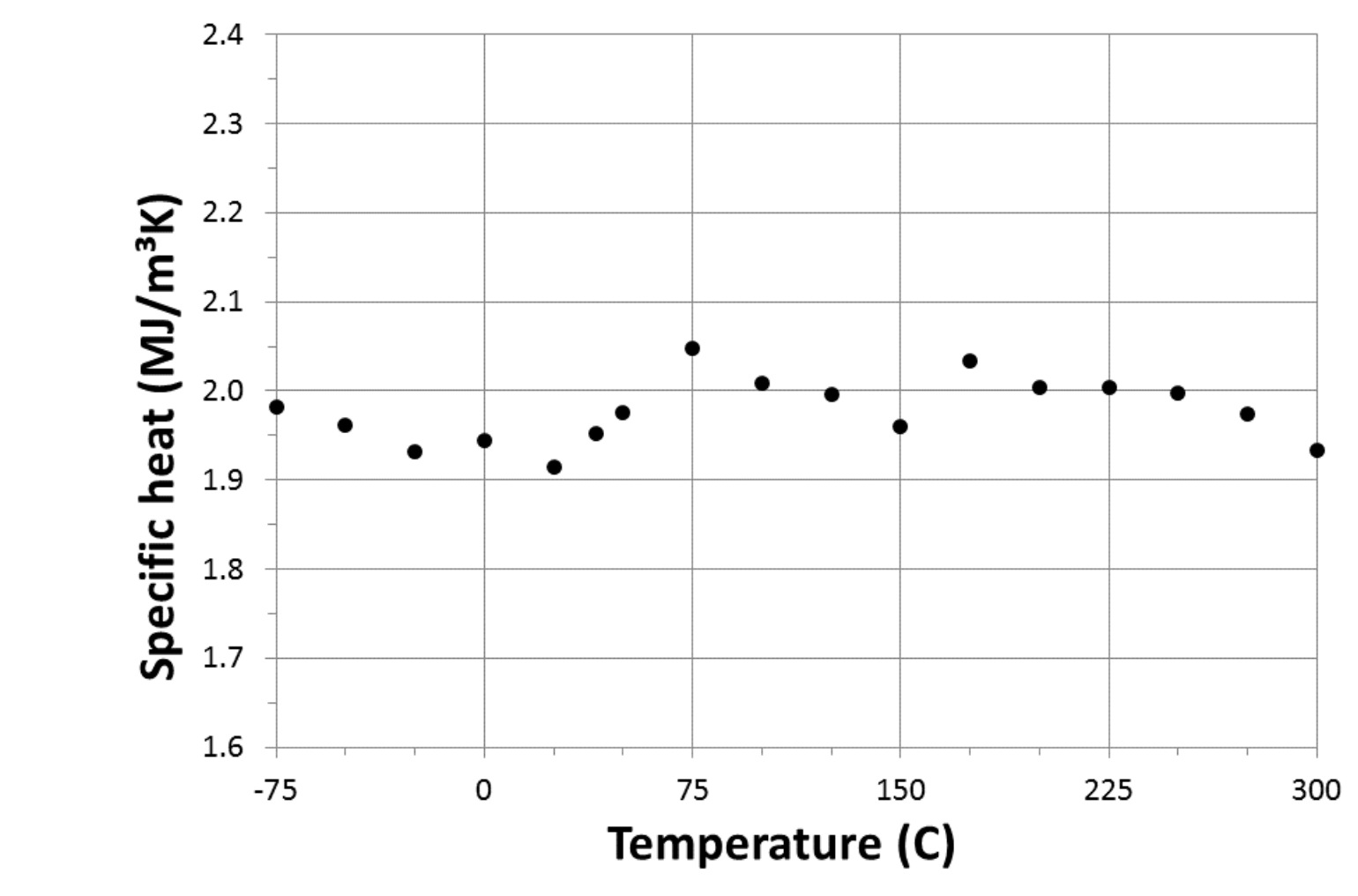

Figure 4

Figure 4

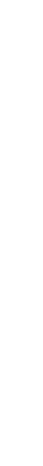

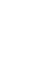
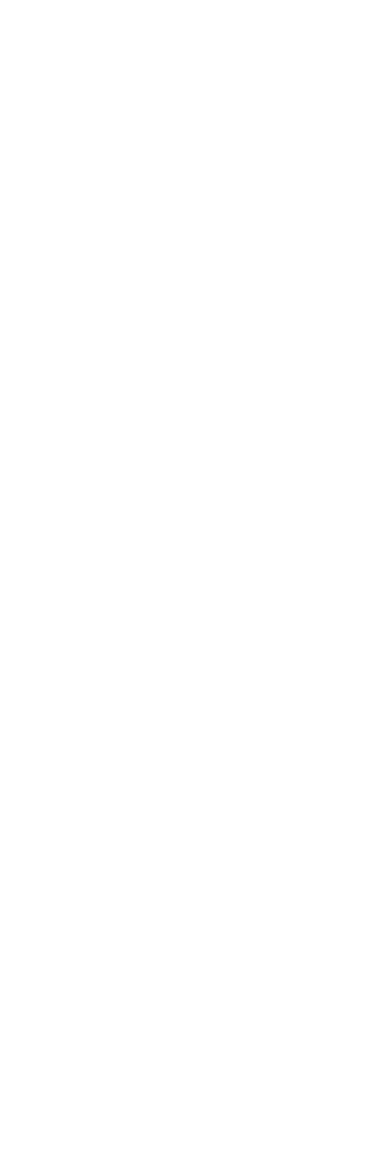